\title{
CETICISMO E RELAÇÕES PEDAGÓGICAS NA OBRA INFÂNCIA, DE GRACILIANO RAMOS
}

\author{
SECTICISM AND PEDAGOGICAL PRACTICES IN THE WORK \\ INFÂNCIA BY GRACILIANO RAMOS
}

\author{
Wagner Ferreira Angelo \\ Universidade do Estado de Santa Catarina \\ w.angelo@hotmail.com \\ Jeane Vanessa Santos Silva \\ Universidade Federal de Santa Catarina \\ jeane_vanessa@hotmail.com
}

\section{RESUM0}

Com base em uma metodologia de investigação qualitativa de cunho filosófico, o presente artigo tem como objetivo discutir a visão cética da criança-personagem no tocante às relações pedagógicas que se desenrolam na obra Infância, de Graciliano Ramos. Infância é a história de uma criança expressa por uma narrativa adulta. A referida obra ilustra a lembrança da infância de um menino repleta de uma série de eventos focados no desenvolvimento e aprendizagem que ocorrem principalmente nos contextos familiar/escolar e urbano/rural. A autoridade é a justificativa usada por pais e professores para oprimir crianças, oferecendo metodologias educacionais voltadas à memorização, à repetição e à punição. Por fim, ressalta-se a influência de modelos educacionais autoritários na educação do século XXI.

Palavras-chave: Ceticismo. Relações Pedagógicas. Educação. Infância

\begin{abstract}
Based on a qualitative research methodology of a philosophical nature, this article aims to discuss the skeptical view of a child-character with regard to the pedagogical practices that unfold in the work Infância Infância by Graciliano Ramos. Infância (Memories) is the story of a child expressed by an adult narration. It illustrates the remembrance of a boy's childhood full of a series of events focused on development and learning that mainly occur in the family/school and urban/rural contexts. Authority is the justification used by parents and teachers to oppress children by offering educational methodologies focused on memorization, repetition and punishment. Finally, the influence of authoritarian educational models in 21st century education is highlited.
\end{abstract}

Keywords: Secticism. Pedagogical Practices. Education. Infância 


\section{Introdução}

Em seu estado mais bruto, antecedente à modernidade, a literatura infantil, seguindo os preceitos arraigados da concepção de infância do século XIII, concebia a criança enquanto "adulto em miniatura", sem maiores preocupações ou investigações sobre as características particulares que constituem uma criança enquanto tal. Com o desencadear de novas formas de configuração social, motivadas principalmente por mudanças estruturais nas relações econômicas, a infância passa a se destacar como uma etapa à parte da vida adulta, levando os familiares e outros grupos sociais a buscarem um tipo de formação que contemple as particularidades das crianças, ao mesmo tempo que se adequa ao modelo econômico capitalista. Tal preocupação, dentre outras razões, foi uma motivação para a criação das escolas.

A necessidade de delegar a outrem o cuidado sobre as crianças ${ }^{1}$ cria a demanda de um serviço tutelar que, em sua forma seminal, acontecia na casa de alguma conhecida da vizinhança, por exemplo. A falta de estabelecimentos formais de ensino também é motivação para que qualquer pessoa alfabetizada pudesse, por livre iniciativa ou como parte de um esforço comunitário, acolher as crianças num espaço improvisado. Nesse local, era fornecido algum nível de alfabetização cujo trabalho, dentre outras possibilidades de suporte textual, envolvia a literatura clássica; esta, por sua vez, não era uma metodologia que levava em conta as especificidades da criança enquanto ser que experimenta a infância. ${ }^{2}$

Como explica Becker (2002), o trabalho com a literatura, todavia, deu-se pelo uso de contos e livros clássicos, sem uma clara caracterização do que viria a ser uma literatura infantil, acarretando na utilização de textos advindos da realidade adulta, servindo de pano de fundo para incorporar nas crianças os conteúdos de natureza moral ou cívica socialmente valorizados em detrimento do modo como as crianças viam/interpretavam o mundo ao seu redor. Ainda de acordo com o autor, escritores como Graciliano Ramos, dentre outros autores, denunciaram a necessidade de uma escrita literária que fosse interessante para o universo infantil, denúncia esta formalizada com a escrita da obra Infância.

Com uma aparente sequência lógica de acontecimentos distintos, o livro Infância (Memórias), uma das vinte e duas obras escritas por Graciliano Ramos, caracteriza-se como um trabalho autobiográfico. Marcada por descrições de espaço e de personagens, bem como pela voz do narrador personagem, a leitura dessa obra leva o leitor a experienciar "um dia após o outro" da infância de Graciliano, incluindo o modo como a criança personagem é constantemente levada a introjetar, por diferentes meios, as verdades veiculadas entre os adultos. Em outras palavras, com base nas discussões de Pierce (2002 [1980]), é possível perceber como os métodos utilizados pelos adultos para saírem de um grau de dúvida (inquietação) para o de crença (aprendizagem) são aplicados indistintamente às crianças por meio da educação familiar e escolar.

\footnotetext{
1 Deve-se levar em conta que a época a qual esta discussão remonta é marcada pelo intenso trabalho infantil de crianças que pertenciam a famílias pobres. Famílias com muitas crianças geralmente delegavam às mais velhas o cuidado das mais novas, de modo que uma parte considerável das crianças não sofria qualquer interferência pedagógica. Dessa situação sócio-historicamente situada decorre uma condição de infância que pode se distinguir entre cada criança (ROCHA, 2003).

2 O termo 'clássico' assume neste trecho uma conotação comum cuja estrutura se revela uma produção da colonialidade. Falar em literatura clássica direciona o leitor diretamente para nomes consagrados da literatura europeia, como se esses nomes fossem representantes de uma literatura universal, e não de uma produção particular espacial e temporalmente situada. As relações entre literatura e alfabetização que aqui traçamos se fundamentam numa percepção eurocêntrica de pedagogia e, mesmo quando recorrermos a Graciliano Ramos para estabelecer tais relações, recorremos a um autor situado num país cuja história foi tecida com elos coloniais.
} 
Porém, o que para os adultos do final Século XIX e início do Século XX aparentam ser conhecimentos inabaláveis do ponto de vista da crença arraigada por tradições, por costumes e pela ciência, para a criança personagem o não convencimento e a permanência na dúvida é sua constante afirmação durante o processo de amadurecimento e aprendizagem. Se a investigação, afirma Pierce (2002 [1980]), é marcada pela saída do estado de dúvida para o da crença, como a criança personagem consegue adquirir novos conhecimentos uma vez que se encontra em constante estado de indagação sobre a realidade à sua volta?

Com base no panorama exposto e ancorado em uma metodologia de investigação qualitativa (MASON, 2002) de cunho filosófico (DENZIN e LINCOLN, 2006), o presente trabalho objetiva discutir a visão cética da criança personagem no tocante às relações pedagógicas que se desenrolam na obra Infância, de Graciliano Ramos.

Para tanto, nas próximas seções, discutiremos, respectivamente, a função da educação autoritária, os distintos métodos de conhecimentos adotados para se chegar a um conhecimento socialmente valorizado, o ceticismo e, finalmente, ofereceremos algumas conclusões.

\section{Uma educação autoritária}

No decorrer da narração da obra Infância (Memórias), é possível verificar como os costumes socialmente estabelecidos, como diferentes preconceitos e noções de moralidade, por exemplo, são pedagogicamente introjetados passando a constituir o desenvolvimento da criança personagem. A cada capítulo, o desenvolvimento do menino se torna mais evidente, aproximando-se do adulto narrador, adulto este que denuncia os valores, considerados como positivos e negativos de sua época, de sua infância, especialmente aqueles veiculados no meio familiar e escolar que, por sua vez, apresentam certa proximidade por adotarem uma intencionalidade pedagógica tradicional com vistas ao crescimento intelectual da personagem.

Essa educação tradicional e disciplinadora encontra fundamentação filosófica, dentre outras fontes, no legado de trabalhos escritos por Immanuel Kant, filósofo alemão do século XVIII. Interessado no desenvolvimento da faculdade humana da razão, ou maturação da razão (do pensamento), Kant (2002) defende que de todos os seres existentes no mundo, o ser humano requer, além da nutrição e dos cuidados que servem para sua evolução biológica, cuidados que servem ao desenvolvimento de suas capacidades racionais. A criança cuja razão foi tutelada sob tais cuidados não será nociva contra si mesma ou contra os outros, uma vez que se apropriou de forma positiva de sua potencialidade racional. Com base nesta concepção, Kant define a educação como o meio pelo qual o homem se tornará um verdadeiro homem, propondo uma metodologia voltada à disciplina cujo foco é o de introduzir o indivíduo às leis que regem o código de conduta humano, repelindo, assim, a selvageria que, grosso modo, seria a independência do homem frente a quaisquer leis. A educação proporcionaria ao homem passar da menoridade para a maioridade da sua razão. ${ }^{3}$

\footnotetext{
3 Kant não se refere ao ser humano em geral enquanto espécie, mas, comprometido com uma ideologia racista, ao homem europeu. Fundamentando-se em teses sem qualquer fundamento científico, Kant trata dos povos não-europeus, especialmente os africanos, como seres que não foram capazes de sair da menoridade da razão e adquirir discernimento moral. Entre outros fatores, o clima seria determinante para criar indivíduos "fortes, corpulentos e ágeis", ao mesmo tempo em que seriam "indolentes, moles e desocupados". Por conta desta condição, tais povos deveriam ser tutelados por aqueles que já haviam atingindo sua maioridade racional, os europeus. O que encontramos aqui é uma legitimação filosófica para a colonização, cujo resultado foi a miséria, o genocídio e a escravização de milhões de seres humanos.
} 
A perspectiva Kantiana de educação encontra ainda mais eco nos contextos familiar e escolar indicados na obra Infância, ao passo que outras formas de conceber a educação das crianças são somatizadas ao princípio disciplinador do século XVIII. Segundo Becker, nesse período

[...] assistiu-se à consolidação de um novo sentimento em relação à criança e à infância. Cada criança passou, então, a ser considerada como um ser único e insubstituível, e a infância foi concebida como um período de fragilidade e inocência, sendo responsabilidade dos pais e educadores buscarem preservar essa inocência ao mesmo tempo em que, através de cuidados com a saúde e a higiene, no plano físico, assim como em relação à disciplina e ao estudo, no plano moral e intelectual, buscavam afastar aquela fragilidade à faixa etária. (BECKER, 2002, p. 140)

A argumentação de Becker elucida o quanto a diferença entre o reconhecimento da criança por seu "estado de ser" (único, frágil e inocente) e o seu reconhecimento como aprendiz (no plano físico, intelectual e moral) era distintamente demarcada. A esse respeito, destacam-se, por exemplo, os momentos de brincadeira como momentos de ser criança em que a criança-personagem interagia com outras crianças e com a natureza em diferentes espaços-tempo narrados. Em contrapartida, ao ser colocado no papel do aprendiz, as atitudes perante o garoto eram outras, mais impositivas e severas.

Sobre a imposição, como indicado por Chartier (2013, p. 421), ao afirmar que as crianças vão "[...] à escola para aprender a ler. E aprender a ler é obrigatório: logo, ir à escola é obrigatório", difundiu-se e instituiu-se que a escola é o lugar de aprendizado exclusivo para se adquirir os conhecimentos mínimos capazes de manter ou ascender determinadas posições socialmente almejadas por seu status. Somada à imposição, a severidade em relação à criança enquanto aprendiz é evidenciada pelo uso da autoridade e do castigo como formas de disciplinar a criança-personagem, gerando uma distância acentuada entre o adulto em relação à criança que, na visão de Boto (2014, p. 113) "[...] estabelece relações de subordinação e dependência" bem marcadas, como segue no excerto a seguir:

O castigo moderado, além de inculcar-me as regras de bem viver, tinha o fim de obrigar-me a vigiar o estabelecimento. [...] Proibiam-me sair, e os outros meninos, distantes, causavam-me inveja e receio. Certamente eram perigosos. Afastado, não possuindo bolas de borracha, papagaios, carrinhos de lata, divertia-me com minhas irmãs, a construir casas de encerado e arreios de animais, no alpendre, e a revolver o milho no depósito. Durante a prisão, lembrava-me desses exercícios com pesar. Entretinha-me remexendo as maravalhas, explorando os recantos escuros, observando o trabalho das aranhas e a fuga das baratas. Divagava imaginando o mundo coberto de homens e mulheres da altura de um polegar de criança. Não me havendo chegado notícia das viagens de Gulliver, penso que a minha gente liliputiana teve origem nas baratas e nas aranhas. Esse povo mirim falava baixinho, zumbindo como as abelhas. (RAMOS, 2015, p. 104)

E ainda:

Deixei-me persuadir, sem nenhum entusiasmo, esperando que os garranchos do papel me dessem as qualidades necessárias para livrar-me de pequenos deveres e pequenos castigos. Decidi-me. [...] Meu pai não tinha vocação para o ensino, mas quis meter-me o alfabeto na cabeça. Resisti, ele teimou - e o resultado foi um desastre. Cedo revelou impaciência e assustou-me. Atirava rápido meia dúzia de letras, ia jogar solo. À tarde pegava um côvado, levava-me para a sala de visitas - e a lição era tempestuosa. Se não visse o côvado, eu ainda poderia dizer qualquer coisa. Vendo-o, calava-me. Um pedaço de madeira, negro, pesado, da largura de quatro dedos. (RAMOS, 2015, p. 110-111) 
Os exemplos acima ilustram a imposição e severidade exercida pela figura do adulto sobre a criança personagem em momentos em que a responsabilidade em ter que aprender a lidar com os negócios da família e com a educação era destacada. Decorre desse comportamento autoritário a reação de medo do menino que, devido aos castigos e punições, obedecia aos comandos impostos por seus pais. Indistintamente do leito familiar, a escola também era uma instância que representava temor à criança-personagem por seu autoritarismo. Um exemplo dessa situação de autoritarismo é relatado logo no início do livro, como segue:

A sala estava cheia de gente. Um velho de barbas longas dominava uma negra mesa, e diversos meninos, em bancos sem encostos, seguravam folhas de papel e esgoelavam-se:

— Um b com um a — b, a: ba; um b com um e — b, e: be.

Assim por diante, até u. Em escolas primárias da roça ouvi cantarem a soletração de várias maneiras. Nenhuma como aquela, e a toada única, as letras e as pitombas convencem-me de que a sala, as árvores, transformadas em laranjeiras, os bancos, a mesa, o professor e os alunos existiram. Tudo é bem nítido, muito mais nítido que o vaso. Em pé, junto ao barbado, uma grande moça, que para o futuro adquiriu os traços de minha irmã natural, tinha nas mãos um folheto e gemia:

- A, B, C, D, E (RAMOS, 2015, p. 10 e 11)

O excerto textual narrado por Graciliano relata um cenário escolar no meio rural no qual as crianças estão sendo alfabetizadas. Na cena, as crianças repetem construções silábicas de várias ordens, provavelmente ditadas pelo professor e repetidas exaustivamente por todos os alunos. Apesar de falar da escola moderna, Boto (2014) explica que, se for necessário para a educação acontecer, a escola deve ser rigorosa e, além disso, citando Comenius a partir do que ele chama de oficina de homens, ela também deve ser dolorosa, ou coercitiva. Em outras palavras, a escola gera um aprendizado voltado à aquisição de noções disciplinares (matérias) e de maneiras. A esse respeito, tratando da cultura escolar, Setephanou e Bastos trazem a seguinte reflexão:

[Ela] pode ser definida como um conjunto de normas que definem conhecimentos a ensinar e condutas a inculcar, e um conjunto de práticas que permitem a transmissão desses conhecimentos e a incorporação desses comportamentos; normas e práticas coordenadas a finalidades que podem variar segundo as épocas (finalidades religiosas, sociopolíticas ou simplesmente de socialização). Normas e práticas não podem ser analisadas sem se levar em conta o corpo profissional dos agentes que são chamados a obedecer a essas ordens e, portanto, a utilizar dispositivos pedagógicos encarregados de facilitar sua aplicação, a saber, os professores primários e os demais professores. (DOMINIQUE, 2001, p. 10/11)

Os métodos de ensino desenvolvidos para disciplinar os alunos, conforme explanado por Dominique, estão de acordo com os preceitos da educação de sua época. Essa constatação explica as razões de a educação familiar e escolar descritas pela criança-personagem estarem voltadas para a doutrinação ou inculcação dos valores morais e intelectuais brasileiros do final do século XVIII e início do século XIX. Em outras palavras, a força, a punição, a repetição e a cópia aplicadas pelos pais e professores (pelo adulto) se caracterizam como medidas educacionais para se atingir o patamar ideal de aprendizado (crescimento moral e intelectual) das crianças.

Todavia, a criança-personagem que era submetida às diretrizes pedagógicas tradicionais autoritárias de sua época sócio-histórica também subvertia esse sistema a partir de sua constante curiosidade, sendo esta a questão a ser tratada na seção seguinte. 


\title{
Fazer educação em diferentes frentes metodológicas
}

Conforme discutido anteriormente, as crianças eram tolhidas pelos adultos por meio de uma autoritarismo constante, característico de um padrão educacional pautado na obediência-subserviente, tanto no ambiente familiar quanto no ambiente escolar. Para além dos sentimentos ocasionados pelo autoritarismo dos pais e professores, a criança-personagem demonstrou ser tímida, observadora e questionadora, o que, por vezes, mobilizou-a a deliberar a respeito dos problemas sociais que apareciam cotidianamente e, na tentativa de compreendê-los, propor explicações racionais para eles. Em contrapartida, a escola impunha uma verdade dogmática a respeito das coisas, explicando os fenômenos do mundo pela informação precisa, através da leitura da literatura nacional e clássica. Em suma, segundo Becker,

\begin{abstract}
A literatura, no âmbito escolar, foi logo percebida pelos educadores como uma poderosa ferramenta de inculcação de valores e comportamentos, visto que ela, mesmo sem apelar diretamente à razão ou disciplina dos aprendizes, mostrava-se capaz de moldar um sentimento nacionalista ou reforçar determinados tipos de crenças, valores e comportamentos prestigiados pela classe dominante. [...] Por muito tempo ficou tacitamente acordado entre escritores de obras infantis, pais e professores, que mereceria a chancela da literatura infantil qualquer obra que estes últimos considerassem, geralmente por critérios de natureza moral ou cívica, apropriada à leitura dos pequenos. (BECKER, 2002, p. 141)
\end{abstract}

Assim sendo, não havia espaço para a dúvida, mas sim uma constante tentativa de manutenção de certezas sobre os valores/conhecimentos que servissem à boa instrução escolar com a finalidade de contemplar o objetivo central da escola: alfabetizar para inculcar valores (BOURDIEU, 2003; SOARES, 2017). É por essa razão que as crianças iam à escola "[...] para aprender a ler. E aprender a ler é obrigatório: logo, ir à escola é obrigatório" (CHATIER, 2013, p. 421). Todavia, como indicado por Becker, Graciliano Ramos considera, pelas experiências da criança-personagem, os textos literários trabalhados no meio familiar e escolar "[...] como falsos e desinteressantes" (BECKER, 2002, p. 144).

Para cumprir seu objetivo, a escola se utilizava de métodos que pudessem auxiliar seus alunos na permuta entre o estado de desconhecimento e o estado de conhecimento de maneira eficaz. Em outras palavras, utilizando os termos de Peirce (2002), o que se buscava era a saída do estado da dúvida (marcado pelo sentimento de indagação, desconforto, insegurança sobre um fato ou fenômeno) para o estado da crença (designado como o sentimento de certeza, conforto, segurança sobre um fato ou fenômeno). Cabe salientar que, no processo de fixação da crença (na busca pela verdade), os métodos empregados pela escola/família não foram métodos de ensino propriamente ditos, pois, para os padrões educacionais do contexto sócio-histórico da obra literária, segundo Boto (2014), os professores desconheciam estes tipos de saberes. As metodologias mencionadas estão voltadas para a resolução da relação dual entre dúvida e crença, ou seja, no desenvolvimento do saber, de maneira mais ampla, extrapolando o contexto escolar, mas, ao mesmo tempo, incluindo-o no modo como as pessoas em seu cotidiano preservam/adquirem/educam os conhecimentos socialmente construídos.

Como proposta de alteração de estado de conhecimento, ainda de acordo com Peirce (2002), quatro métodos são propostos, quais sejam: o da tenacidade, o da autoridade, o do a priori e o científico. Tanto o método da tenacidade quanto o da autoridade têm em comum o fato de considerarem uma crença (ou um conjunto de crenças particulares) como sendo irrefutáveis. 
Todavia, a distinção que marca ambas as metodologias de investigação pode ser apontada da seguinte maneira: enquanto o método da tenacidade diz respeito ao modo como cada indivíduo concebe, a seu modo (individualmente), uma crença para, rapidamente, manter-se afastado (solucionar) da dúvida, o método da autoridade impõe à coletividade uma crença que também os afasta da dúvida por vias da naturalização de uma certeza que é sutilmente introjetada no coletivo e mantida por meio da autoridade. Assim, é possível estabelecer uma diferença de métodos de investigação marcada pela relação individual-coletiva (tenacidade: minha crença em relação a dos demais) e coletiva-individual (autoridade: nossa crença em oposição àquela individual), ambas estão fadadas a julgar como certas possíveis falsidades socialmente disseminadas, conforme indicado nos fragmentos textuais seguintes:

Diante disso, invoquei a autoridade do professor, que devia conhecer bem Samuel Smiles. O professor dizia Smailes. Mentira, gritou Fernando - injustiça, pois eu não sabia mentir. Cobriram-me de motejos e resolveram adotar a opinião do mulato: Samuel Símiles. Arriei, vencido (RAMOS, 2015, p. 215).

E ainda:

A exaltação diminuiu, o pranto correu manso, estancou, e uma vozinha triste confessou-me, entre longos suspiros, que o mundo ia acabar. Estremeci e pedi explicações. la acabar. Estava escrito nos desígnios da Providência, trazidos regularmente pelo correio. Na passagem do século um cometa brabo percorreria o céu e extinguiria a criação: homens, bichos, plantas. Riachos e açudes se converteriam em fumaça, as pedras se derreteriam. Antigamente a cólera de Deus exterminara a vida com água; determinava agora suprimi-la a fogo. [...] Eu ignorava o século, os cometas, a tradição. E estendia fraternalmente a minha ignorância a todos os indivíduos. Não percebendo o mistério das letras, achava difícil que elas se combinassem para narrar a infeliz notícia. Provavelmente minha mãe se tinha equivocado, supondo ver na folha desastres imaginários. Expus esta conjectura, que foi repelida. A desgraça estava anunciada com muita clareza. Olhei o muro de tijolo, considerei-o indestrutível. (RAMOS, 2015, p 76)

Os excertos supracitados demonstram, respectivamente, como as metodologias de investigação da tenacidade e autoridade eram utilizadas para educar a criançapersonagem, no sentido de introjetar-Ihe um conjunto de crenças. No primeiro caso, verifica-se que distintos pontos de vista são empregados para pronunciar o nome de uma das personagens, não permitindo que um consenso seja atingido a respeito do problema. No segundo caso, ao tratar do fim do mundo, a mãe do menino tinha um conjunto de crenças advindas de sua relação direta com a religião cristã, compartilhada com um grupo de crentes, imbuindo a mão de certa autoridade para tratar do assunto. A reação do menino em ambas as situações apresentadas foi a de aceitar, passivamente, a imposição dos adultos que estavam investidos da verdade sobre o assunto em pauta.

Nos casos dos métodos a priori e científico, a razão é um ponto em comum, uma vez que seria por meio da razão que ambos os métodos introjetariam a crença. O modo como cada abordagem utiliza a razão é justamente o que as diferencia. Enquanto o método a priori toma a razão como produtora e legitimadora do conhecimento, afastando o papel da experiência do processo epistemológico; o método científico se apropria da razão e da experiência, para formar um conjunto de crenças que são fundamentadas tanto pelas experiências cotidianas quanto pela investigação racional. O método científico seria então capaz de oferecer preceitos que, uma vez seguidos, são capazes de reproduzir um resultado, comprovando com a experiência a validade de uma ideia. $O$ método científico não é utilizado pelas personagens do livro Infância (Memórias), mas o exemplo abaixo retoma o método a priori: 
Livrara-me do aperto crismando as consoantes difíceis: o T era um boi, o D uma peruinha. Meu pai rira da inovação, mas retomara depressa a exigência e a gravidade. Impossível contentá-lo. E o côvado me batia nas mãos. Ao avizinhar-me dos pontos perigosos, tinha o coração desarranjado num desmaio, a garganta seca, a vista escura, e no burburinho que me enchia os ouvidos a reclamação áspera avultava. Se as duas letras estivessem juntas, o martírio se reduziria, pois, libertando-me da primeira, a segunda acudia facilmente. Distanciavam-se, com certeza havia na colocação um desígnio perverso - e os meus tormentos se duplicavam. (RAMOS, 2015, p. 112 e 113)

Considerando os exemplos mencionados para se trabalhar a descoberta do conhecimento nos meios familiar e escolar, infere-se que o desejo de mudança de estado da dúvida à verdade ocorria pela transmissão e imposição de crenças já estabelecidas, desestimulando os alunos que, diante da pressão em memorizar o máximo de informações possível, acabavam correspondendo parcialmente às expectativas de seus mentores, satisfeitos ao constatarem a obediência de seus discípulos. Porém, também é possível observar que a criança-personagem propunha estratégias de aprendizagem aguçadas por sua curiosidade e imaginação ao tentar explicar determinado fenômeno que não a satisfazia intelectualmente. Por sua vez, esse olhar diferenciado conduz a uma nova possibilidade de consideração a respeito do pensar a verdade, de conhecer algo. A essa outra forma de ciência, dá-se o nome de ceticismo, ponto tratado na seção seguinte.

\section{0 ceticismo como recurso investigativo em alfabetização}

Em várias passagens da obra, a criança-personagem se mostra interessada em aguçar os seus sentidos sobre o mundo que a cerca e, diante de fenômenos sobre os quais conseguia compreender a lógica de funcionamento, questionava-se quanto às explicações que recebia dos adultos, por vezes, proferindo sentenças do tipo "O juízo dos homens era esquisito. Bem esquisito" (RAMOS, 2015, p. 58). Tal posicionamento de insatisfação de ordem intelectual, característico das crianças na famosa "idade dos porquês", tem uma relação direta com o olhar cético, ou o olhar questionador/duvidoso.

Segundo Costa (2012), o Ceticismo, grosso modo, como é conhecido por estudiosos como Montaigne, Descartes e Hume, apesar de suas divergências, constitui-se da afirmativa de que a dúvida (ou o ato de duvidar) é um elemento que permite o alcance de um conhecimento mais seguro, configurando, assim, de acordo com Sexto Empírico, o cético como sendo aquele sujeito que não acredita na descoberta inalterável/irrefutável da verdade. Em outras palavras, ser cético faz menção ao fato de que a coletânea de argumentos possíveis que expliquem um dado fenômeno não será suficiente para se atingir um grau absoluto (universal) de satisfação, de modo a estabelecer um verdade irrefutável. Um exemplo se dá quando a criança-personagem ao dialogar com o pai ouve deste a explicação de que o domínio da leitura fornece àquele que o possui força e poder:

Demorei a atenção nuns cadernos de capa enfeitada por três faixas verticais, borrões, nódoas cobertas de riscos semelhantes aos dos jornais e dos livros. Tive a ideia infeliz de abrir um desses folhetos, percorri as páginas amarelas, de papel ordinário. Meu pai tentou avivar-me a curiosidade valorizando com energia as linhas mal impressas, falhadas, antipáticas. Afirmou que as pessoas familiarizadas com elas dispunham de armas terríveis. Isto me pareceu absurdo: os traços insignificantes não tinham feição perigosa de armas. Ouvi os louvores, incrédulo. (RAMOS, 2015, p. 109) 
Tipos mais moderados de céticos costumam seguir as normas e costumes da vida comum (cotidiana) por acreditar que apreendemos a realidade pelos nossos sentidos, ou seja, as experiências que advém de como as coisas se apresentam no mundo sendo capazes de gerar determinados conhecimentos, não interessando, neste caso, explicarmos essa realidade por reflexões filosóficas. ${ }^{4} \mathrm{~A}$ versão cética mais antiga, o ceticismo pirrônico, compreendia a posição cética como um processo em busca da tranquilidade da alma (ataraxia), por este motivo, tal abordagem também é conhecida como ceticismo terapêutico, uma vez que "o ceticismo de Pirro não deve ser encarado como algo que se limita a uma teoria cética, mas a uma experiência prática de busca pela quietude, uma proposta de terapia" (SILVA, 2013, p 16.).

Diante da possibilidade de sujeitos que debatem determinado tema apresentarem razões e argumentos indefinidamente a fim de defender a verdade do seu ponto de vista, a melhor posição seria suspender o juízo (epoché) e negar a verdade absoluta de qualquer conclusão, permitindo, assim, a continuidade da investigação. ${ }^{5}$ Em outras palavras, uma vez que sempre se pode prolongar uma discussão adicionando um argumento que refuta uma pretensa verdade colocada, havendo então a necessidade de respondê-lo e portanto continuar a discussão, a melhor posição seria não ter posição, e defender a impossibilidade de se atingir a verdade por quaisquer meios.

Assim sendo, de modo a complementar a definição pirrônica anteriormente exposta, que afirma o ceticismo enquanto método para se alcançar a "tranquilidade (ataraxia) ou a ausência de perturbação da alma", Sexto Empírico (1997), ainda define o ceticismo como um modo de perceber, refletir e expressar os fatos/conhecimentos/saberes/atitudes no mundo a partir de uma constante insatisfação dos sujeitos sobre as respostas prontas. Com isso, ele atribui ao cético a figura de investigador que, por meio de contra-argumentos, tantos quanto necessários, busca amadurecer suas ideias sobre uma dada hipótese. Essa inconformidade dos sujeitos acaba pondo os conhecimentos em quarentena, possibilitando ao cético a liberdade de conhecer novos modos de apreciar este saber, evitando a dependência intelectual de dominação e controle unidirecionada pelo objeto (conhecimento) em relação ao sujeito. Tal incômodo é expresso pela criança personagem pela inconveniência com a literatura veiculada nas escolas de seu tempo, motivando-a a buscar outras fontes literárias que promovessem a satisfação da curiosidade. Tal comportamento resulta no encontro entre a criança personagem e as obras colecionadas por Jerônimo Barreto:

Dirigi-me a casa, subi a calçada, retardei o passo, como de costume, diante das procurações e públicas-formas. E bati à porta. Um minuto depois estava na sala, explicando meu infortúnio, solicitando o empréstimo de uma daquelas maravilhas. Mais tarde me assombrou o arranco de energia, que em horas de tormento se reproduziu. Como veio semelhante desígnio? De fato não houve desígnio. Foi uma inexplicável desaparição da timidez, quase a desaparição de mim mesmo. Expressei-me claro, exibi os gadanhos limpos, assegurei que não dobraria as folhas, não as estragaria com saliva. Jerônimo abriu a estante, entregou-me sorrindo O Guarani, convidou-me a voltar, franqueou-me as coleções todas. (RAMOS, 2015, p. 231)

\footnotetext{
4 É necessário diferenciar formas globais de ceticismo de formas locais de ceticismo. Enquanto uma forma global de ceticismo instaura a dúvida e consequentemente uma defesa da impossibilidade de oferecer uma justificação irrefutável para qualquer tipo de conhecimento, uma forma local de ceticismo lança dúvida sobre a possibilidade de justificar um tipo específico de conhecimento formado por meio de um processo específico. O argumento cartesiano do gênio maligno, por exemplo, é uma forma global de ceticismo, uma vez que coloca sob dúvida nossa capacidade de fornecer justificação para o conhecimento de qualquer aspecto da realidade extra-mental ou da realidade mental, assim qualquer processo formador de crenças disponível ao sujeito é considerado falho. O tipo de ceticismo que é possivel observar no comportamento cético de Graciliano Ramos em sua infância é uma forma local de ceticismo, uma vez que a criança não duvida da capacidade de conhecer qualquer fenômeno, mas mantém a dúvida diante de argumentos de autoridade específicos que pretendem explicar fenômenos específicos. Do ponto de vista filosófico, o ceticismo de Graciliano é louvável, pois demonstra atitude crítica.

5 De acordo com o ceticismo pirrônico, três atitudes doxásticas (em relação à crença) são possíveis: a crença, a descrença e a suspensão de juízo. A crença é configurada por um estado psicológico positivo em relação a uma dada proposição; a descrença é configurada pelo estado psicológico de negação em relação a uma dada proposição e a suspensão de juízo é a não tomada de posição em relação a uma dada proposição. A suspensão de juízo é conveniente quando o indivíduo não tem razões suficientes para acreditar ou desacreditar de uma proposição.
} 
No que diz respeito ao modelo autoritário de educação presente na obra Infância (Memórias), a criança personagem, movida pelo olhar cético que não se conforma a explicações dogmáticas, parece instigar-se pela leitura de obras outras que satisfaçam a sua curiosidade em compreender outras sensações e experiências existentes fora dos compêndios escolares. Segundo discute Bianchi (2015), um modelo de educação que adote os preceitos do Ceticismo apresenta, dentre outros pontos, os seguintes resultados no que diz respeito ao processo de aprendizagem dos estudantes: A) construção de sujeitos ativos em busca de explicações (argumentos) para as suas inquietações a partir da investigação, inclusive, de saberes cujo campo inóspito é percorrido com cautela; B) desenvolvimento de expressividade sobre o ser/estar dos estudantes sem imposição de modelos; C) participação autônoma sobre a busca de opiniões especializadas, distanciando-se da falsidade ou conhecimentos frágeis em termos de argumentação/justificativa; D) dúvida (questionamento/problematização) quanto aos conhecimentos novos; e E) busca de respostas mais conclusivas, mas passíveis de redefinição/transformação/atualização/adequação/revisão.

Utilizar o modelo cético como método pedagógico não é novidade. Michel de Montaigne (1987), em seu ensaio intitulado Da educação das crianças, já tecia no século XVI veemente crítica contra o ensino autoritário que se fundamentava em saberes estabelecidos pela tradição dogmática. Transparecendo verdadeira aversão à escola, Montaigne, assim como Graciliano Ramos, relata uma experiência escolar traumática, com exigências e punições que, além de incompreendidas pelas crianças, contribuíam para o apagamento da capacidade criativa, transformando-as em adultos incapazes de pensar por si mesmos, uniformizados.

Tomando a dúvida como parte constituinte do ser humano, Montaigne propõe uma educação que se dê por meio da experimentação, só a experimentação da vida seria capaz de formar no indivíduo a capacidade de livre deliberação. Aceitar crenças estabelecidas de modo dogmático e irrefletido seria o mesmo que negar a própria natureza humana. Um olhar cético é um olhar questionador capaz de levar a uma atitude crítica diante dos fenômenos, de modo a tornar o estudante um agente do processo epistemológico, em vez de mero receptor passivo e acrítico.

\section{Considerações finais}

Infância (Memórias) é a história de uma criança expressa pela narração de um adulto. A rememória da infância desencadeia a lembrança de uma série de acontecimentos voltados para o desenvolvimento e aprendizado ocorridos, principalmente, nos leitos familiar e escolar nos quais as experiências com o mundo urbano e rural acontecem como decorrência das relações sociais vividas pela criança-personagem. A autoridade é a justificação utilizada pelos pais e professores para oprimirem as crianças oferecendo uma educação metodologicamente voltada para memorização, repetição e punição; as crianças aprenderiam pela força e não pela vontade. Todavia, mesmo inscrita em contextos impositivos de saberes enciclopédicos, a curiosidade da criança-personagem vai além das informações pré-fabricadas e veiculadas pelos adultos, mostrando o quanto as suas experiências do dia-a-dia a conduzem-na a uma indagação constante dos fenômenos sociais dos quais participa e observa.

A partir desse panorama geral da obra literária escrita por Graciliano Ramos, buscou-se neste trabalho discutir a importância da visão cética da criança personagem em relação ao processo de alfabetização do leito familiar ao escolar na obra Infância. Para tanto, foram expostas as formas metodológicas de investigação empregadas pelos adultos tanto no meio familiar quanto no escolar que, indistintamente, preocuparam-se em consolidar o perfil de uma criança leitora e escritora passiva e receptiva aos costumes evalores de sua época. 
No entanto, de modo subversivo, o menino, que estava em processo de alfabetização ao longo da obra, mostrou-se inquieto em relação às proposições dos adultos para explicar os fenômenos do mundo. Com isso, entre desafios e questionamentos, ele buscou novas alternativas de compreender os acontecimentos que o circundavam, bem como aprender o processo de leitura e escrita, incorporando um desejo pela aquisição de outros conhecimentos literários que satisfizessem à sua curiosidade.

A partir desses argumentos, é possível considerar pertinente a releitura do ambiente escolar e familiar, tendo em vista a constante curiosidade da criança em relação aos modos de apreender e explicar os determinados fatos e fenômenos. Evita-se, assim, que modelos educacionais autoritários, como aqueles tradicionalmente empregados nas escolas do final do século XIX e início do século XX, ainda incidam suas forças dogmáticas sobre a educação do século XXI.

\section{Referências}

BECKER, Paulo. Natureza e funções da literatura infantil. In: ROSINE, Jania Maria K.; BECKER, Paulo (Orgs.). Leitura e animação cultural: repensando a escola e a biblioteca. Passo Fundo: JPF, 2002. p. 139-151.

BIANCHI, Vinícius Cezar. Ceticismo e educação, por que não?. Enciclopédia. Pelotas. Vol. 03. 2015. p. 155-165. BOURDIEU, Pierre. Language \& Symbolic Power. Cambridge: Editora Harvard University Press, 2003.

BOTO, Carlota. A Liturgia da Escola Moderna: Saberes, valores, atitudes e exemplos. R. Hist. Educ. Porto Alegre. Vol. 18, No 44, Set./Dez. 2014. p. 99-127.

CHARTIER, Anne-Marie. Paradoxos da obrigatoriedade escolar. In: VIDAL, Diana Gonçalves; AS, Elizabeth Figueiredo de; GASPAR da SILVA, Vera Lucia (Orgs.). Obrigatoriedade Escola no Brasil. Cuiabá: EdUFMT, 2013. p. $421-438$

COSTA, Rogério Soares da. Notas curtas sobre o ceticismo moderno contemporâneo. Ensaios Filosóficos. Vol. 05. Abril. 2012. p. 22-40.

DENZIN, N. K.; LINCOLN, Y. S. O planejamento da pesquisa qualitativa - Teorias e abordagens. Porto Algre: Artmed, 2006.

KANT, Immanuel. Das Diferentes Raças Humanas. Tradução e notas de Alexandre Hahn. Kant e-Prints. Campinas, Série 2, v. 5, n. 5, p. 10-26, número especial, jul.- dez., 2010.

KANT, Immanuel. Sobre a pedagogia. Piraicaba: Editora UNIMEP, 2002.

MASON, J. Qualitative Researching. Los Angeles: Editora SAGE, 2002.

MONTAIGNE, Michel de. Da educação das crianças. In: Ensaios. Coleção Os Pensadores, São Paulo: Nova Cultural, 1987. p 73-89.

PEIRCE, Charles Sanders. Três Escritos sobre o Pragmatismo. Philip Weiner, 2002.

QUIJANO, Aníbal (2005). "Colonialidade do poder, Eurocentrismo e América Latina". In: Lander, Edgardo (comp.). La colonialidad del saber: eurocentrismo y ciencias sociales. Perspectivas latinoamericanas. Buenos Aires: CLACSO.

RAMOS, Graciliano. Infância - Memórias. 48ª Edição. Rio de Janeiro: Editora Record, 2015.

ROCHA, E. A. C. A função social das instituições de educação infantil. Zero-a-seis, v. 05, n. 07, p. 01-10, 2003.

SOARES, Magda. Linguagem e escola - Uma perspectiva social. São Paulo: Contexto, 2017.

STEVENSON, J. T. On doxastic responsability. In: LEHRER, K. (Org.). Analysis and Metaphysics. Dordrecht: Reidel, 1975. 
EMPIRICO, Sexto. Hipotiposes Pirrônicas Livro I. O que nos faz pensar, v. 9, n. 12, p. 115-122, 1997. Disponível em: <http://www.oquenosfazpensar.fil.puc-rio.br/index.php/oqnfp/article/view/130>. Acessado em 10/12/2020.

SILVA, J.V.S. Uma defesa contextualista da justificação epistêmica. 2013. Dissertação de mestrado - Programa de Pós-Graduação em Filosofia da Universidade Federal da Paraíba, João Pessoa.

JULIA, D. A cultura escolar como objeto histórico. Revista Brasileira de História da Educação, n. 01, p. 09-43, 2001.

Recebido em: 11/02/2021

Aceito em: 17/05/2021 